\title{
O Nome da Rosa - Leitores Possíveis
}

Cláudio Obayashi ${ }^{1}$

Todo livro é suscetível de pelo menos duas leituras. Uma, a das palavras escritas; a segunda, a do que está nas entrelinhas. Em sua ficção de estréia $\boldsymbol{O}$ NOME DA $\boldsymbol{R O S A}^{\mathbf{1}}$ (1983, Editora Nova Fronteira, Tradução de Aurora Fornoni Bernardini e Homero Freitas de Andrade, 562 páginas), o crítico literário italiano Umberto Eco fez um texto capaz de gerar leituras sempre diversas, mas ao mesmo escrito para poucos.

Como o próprio autor cita em sua outra obra SEIS PASSEIOS PELOS BOSQUES DA FICÇÃO': “(...) Os leitores empíricos poder ler de várias formas, e não existe lei que determine como devem ler...”. Nesta mesma obra, Umberto Eco diz que o autor-modelo deve prever um leitor-modelo, que se supõe capaz de enfrentar as expressões de maneira interpretativa, do mesmo modo que o autor as encara de maneira gerativa.

O leitor-modelo de $\boldsymbol{O}$ NOME DA ROSA deve ser um erudito em Latim clássico e em história medieval. Alguém que possa compreender as inúmeras passagens sem tradução mantidas em Latim, alguém que se interesse pelas descrições dos episódios históricos, da filosofia, da política, do clero e do ambiente que dominava as abadias beneditinas entre os anos de 1316 a 1334, quando João XXII era o Papa, ou ainda alguém que seja especializado em línguas medievais, que possa compreender as citações do personagem Salvatore.

Os leitores empíricos por sua vez poder ter vários tipos de interesse. O primeiro, mais evidente, é pelo enredo central da história. O frei franciscano inglês Guilherme de Baskerville e seu aprendiz Adso de Melk chegam a uma abadia beneditina no norte da Itália onde sete mortes misteriosas ocorrem durante os sete dias em que ali permaneceram. Frei de Baskerville, utilizando de grande poder de lógica e indução, começa a investigar estas mortes misteriosas e chega à conclusão de que todas estão relacionadas a um livro, que, ao final do romance, revela-se ser o segundo livro da Poética escrito por Aristóteles, escondido numa das partes da Biblioteca que faz parte do complexo da Abadia.

Um segundo tipo de leitor pode se interessar pelas semelhanças entre certos personagens e outros elementos tanto do mundo da ficção quanto do mundo real. Primeiramente, os dois personagens centrais: Guilherme de Baskerville e Adson de Melk. É inevitável a ligação com Sir Arthur Conan Doyle e seus principais personagens: Sherlock

\footnotetext{
${ }^{1}$ Cláudio Obayashi é licenciando em Letras Inglês na Universidade Federal do Paraná.
} 
Holmes - detetive conhecido pela sua incrível capacidade de indução e Dr. Watson, seu famoso assistente (a rima entre Watson e Adso (Adson, em outras traduções) é elementar...). Com relação ao nome Baskerville, logo nos remetemos a uma de suas mais famosas obras, $\mathrm{O}$ Cão de Baskerville. Já no mundo real, há a semelhança entre o nome do vilão da estória, Jorge de Burgos, e o autor argentino Jorge Luís Borges - ambos são cegos. Borges apresenta duas grandes semelhanças de estilo se comparado a Umberto Eco. Logo na introdução, o autormodelo cita que a obra foi baseada em um manuscrito que veio parar em suas mãos. Este recurso também se faz presente nas obras de Borges. O conto TLÖN, UQBAR, ORBIS TERTIUS ${ }^{3}$ é um bom exemplo. Outra semelhança é a paixão de ambos os autores pelos labirintos. Veja o exemplo do conto A BIBLIOTECA DE BABEL ${ }^{3}$.

Aqui pode-se analisar um terceiro tipo de leitor empírico: aquele que verifica a importância do labirinto da biblioteca ao longo do romance. É interessante verificar que, num livro onde há tantos personagens com extrema riqueza psicológica, o autor prefere dedicar parágrafos muito longos, ou às vezes até páginas (por exemplo, quando narra o momento que Adson se depara com o portal da igreja, levando seis páginas ${ }^{4}$ para esmiuçar o aludido portal), descrevendo as características arquitetônicas da Abadia. Para muitos leitores, tal lentidão no ritmo da estória poderia ser caracterizado como longos momentos de digressão do narrador. Mas para este leitor que vê na figura da Biblioteca o verdadeiro protagonista do romance, várias análises poder ser feitas. A começar pelo significado de um labirinto. Ele esconde a verdade e oferece mentiras. Quanto mais habilmente ocultar a verdadeira solução, mais ele será interessante. E Eco fez justamente que a Biblioteca da Abadia estivesse instalada em um edifício em forma de labirinto, onde as salas apresentavam charadas, algumas contendo armadilhas, interligadas através de caminhos confusos. Este leitor pode buscar no seguinte trecho um argumento para comprovar sua idéia que o Edifício da Biblioteca trata-se na verdade do protagonista: “(...) Eu não tinha a experiência de um mestre-pedreiro, mas logo me dei conta de que ele (i.e. o Edifício) era muito mais antigo que as construções que o rodeavam, nascido talvez para outros fins, e que o conjunto abacial fora se dispondo ao redor dele em tempos posteriores, mas de modo que a orientação da grande construção se adequasse à da igreja, ou esta àquela.”. 5

A mesma Biblioteca pode servir de moto para um quarto tipo de leitor: o que vê a crítica de Eco à Igreja Católica nas entrelinhas quando descreve o Edifício, por exemplo, no seguinte diálogo entre Guilherme de Baskerville e Adson: “(...) E então uma biblioteca não é um instrumento para divulgar a verdade, mas para retardar sua aparição?” - pergunta 
Adson. Responde Guilherme: “Não sempre e não necessariamenteNeste caso é.” . 6 Ou seja, do ponto de vista de Eco, ou de seu autor-modelo, a Igreja medieval teve em suas mãos a possibilidade de divulgar o conhecimento, mas preferiu guardá-lo para si, como uma forma de controle e manipulação. Uma alegoria que talvez passe despercebida é a posição do cemitério em relação a Abadia e o Edifício. Há um mapa ${ }^{7}$, o qual comprova que o cemitério fica localizado exatamente entre ambos, ou seja, entre a religião (edifício abacial) e o saber (edifício da biblioteca), estava a morte. Além disso, percebe-se ao longo do romance uma apologia à Igreja pré-medieval, quase sem adornos ou riquezas materiais, simbolizada novamente pela Biblioteca, apoiada sobre uma estrutura de pedra, enquanto o resto das construções da abadia apresentam muitos adornos e artefatos de grande valor, mas estas construções ficam localizadas sobre os vilarejos e camponeses famintos que habitavam em torno da abadia. Há ainda os longos debates entre Guilherme de Baskerville e Jorge de Burgos em torno do riso e do racionalismo. Este anti-racionalismo é a chave que explica todos os mistérios da Abadia e de sua Biblioteca, desde as primeiras mortes até o assassinato do Abade, passando pelas lutas entre hereges e a Inquisição, entre o Papa João XXII e o Imperador Ludovico. O anti-catolicismo de Eco também se revela nas diferentes formas investigativas utilizadas por Guilherme de Baskerville e Bernardo de Gui, personagem que representa a Santa Inquisição. O primeiro utiliza seus raciocínios dedutivos e lógicos, como se fosse um cientista, e não um clérigo. Ao decidir pelas pessoas que serão interrogadas, opta por iniciar sua investigação pelos próprios monges beneditinos, ou seja, a ciência sem pudor de interrogar o clero. Bernardo por sua vez inicia suas investigações inquirindo apenas os outros habitantes da abadia, aqueles que não tinham qualquer relação com nenhuma ordem religiosa. Há um certo requinte de corporativismo neste comportamento. E ao condenar Salvatore, Remigio e a camponesa por heresia e bruxaria, baseia-se em teses carregadas de misticismo e superstição, princípios completamente anti-racionalistas. Além disso, faz uso de técnicas de tortura tanto físicas quanto psicológicas para obter confissões, tudo para satisfazer seu ego.

Um quinto tipo de leitor pode se ater aos aspectos técnicos da narrativa, como o tempo e o narrador da estória. O tempo da história ocorre em sete dias, e cada dia é dividido nos períodos correspondentes às horas litúrgicas, ou seja, nas partes que a Igreja usava para que seus clérigos rezassem: Matinas, Laudes, Primeira, Terceira, Sexta, Nona, Vésperas e Completas. Ao longo desses dias, alguns clérigos vão aparecendo mortos, seguindo de uma certa forma a mesma seqüência dos eventos apocalípticos descritos na Bíblia Sagrada, no livro de Revelações de João. Por exemplo, da mesma forma que João revela que o mundo 
terminará num lago de fogo, o último personagem importante morre num incêndio que ocorre no Edifício. Poucos são os momentos de flashback e flashforward ao longo da narrativa, os quais não interferem em nada na compreensão da obra. A utilização destes recursos é feita, por exemplo, para descrever a origem de certas ordens religiosas e o destino de certos personagens (considerando como tempo zero o tempo da narração, ou seja, Novembro de 1327), caracterizando momentos de digressão por parte do narrador. Ou seja, a rapidez de ritmo defendida pelo também italiano Italo Calvino em suas SEIS PROPOSTAS PARA O PRÓXIMO MILÊNIO ${ }^{8}$ não se faz presente ao longo do tempo de discurso da obra de Eco. A narração é feita por um narrador onisciente, representado pelo personagem Adson de Melk.

Romance policial, alta literatura, tratado de história da idade média, tratado de semiótica, inúmeras são as formas de classificar esta obra. Justamente essa diversidade interpretativa fez desse romance um grande sucesso, apesar de sua enorme complexidade narrativa, principalmente em nível léxico, semântico e filosófico. Analisando o ponto de vista de Vergílio Ferreira em seu ensaio DA VEROSIMILHANÇA - “(...) Mas, se justamente um conceito geral de um determinado gênero literário varia com o tempo, compreendemos que um conceito de verossimilhança varie também." 9 - conclui-se que a indeterminação do gênero literário presente na obra $\boldsymbol{O}$ NOME DA ROSA faz com que sua verossimilhança seja atemporal. A multiplicidade de leituras possíveis da obra de Eco forma um verdadeiro labirinto. Os leitores empíricos sentem-se motivados a descobrir uma alternativa para este labirinto, o qual apresenta várias saídas e nenhuma delas pode ser considerada melhor ou pior do que a outra. O autor-modelo, na página 361, diz: “(...)Os livros não são feitos para acreditarmos neles, mas para serem submetidos a investigações. Diante de um livro não devemos nos perguntar o que diz mas o que quer dizer, idéia que os velhos comentadores dos livros sagrados tiveram claríssima.” E indubitavelmente o autor empírico, Umberto Eco, atinge a plenitude deste conceito. Não existem limites de investigações ao livro $\boldsymbol{O}$ NOME DA ROSA. Em última instância, haverá sempre a dúvida do porquê do nome da obra. $\boldsymbol{O}$ NOME DA ROSA, com certeza, ainda atravessará o terceiro milênio como um dos maiores romances do século $\mathrm{XX}$.

\section{REFERÊNCIAS}

1. ECO, Umberto. O nome da rosa; tradução de Aurora Bernardini e Homero Freitas de Andrade. - Rio de Janeiro: Nova Fronteira, 1983. 
2. ECO, Umberto. Seis passeios pelos bosques da ficção; tradução de Hildegard Feist. - São Paulo: Companhia das Letras, 1994, p. 14.

3. BORGES, Jorge Luis. Ficções; tradução de Carlos Nejar. - São Paulo: Editora Globo, 2001.

4. ECO, Umberto. O Nome da rosa; tradução de Aurora Bernardini e Homero Freitas de Andrade. - Rio de Janeiro: Nova Fronteira, 1983, pp. 57-62.

5. Idem. Ibid. p. 41.

6. Idem. Ibid. p. 330.

7. Idem. Ibid. p.33.

8. CALVINO, Italo. Seis propostas para o próximo milênio: lições americanas; tradução de Ivo Barroso. - São Paulo: Companhia das Letras, 1990.

9. FERREIRA, Vergílio. "Da verossimilhança" / Vergílio Ferreira. In: Revista Colóquio/Letras. Ensaio, n. ${ }^{\circ}$ 8, Jul. 1972, p. 7. 